\title{
EL LÉXICO DE LA FELICIDAD Y DE LA LENTITUD EN LA DIDÁCTICA DE DOS POETAS: ALFONSO CANALES Y LUIS ANTONIO DE VILLENA ${ }^{1}$
}

THE LEXICON OF HAPPINESS AND SLOWNESS IN THE DIDACTICS OF TWO POETS: ALFONSO CANALES AND LUIS ANTONIO DE VILLENA

Antonio PORTELA LOPA Universidad de Burgos

Resumen: En este trabajo vamos a estudiar dos grupos léxicos: el de la felicidad y el de la lentitud, ambos en el uso didáctico que les dan dos poetas: Alfonso Canales (en su poema «Los años»), y Luis Antonio de Villena, («Lectura de las Geórgicas»). Se examinan las diferencias y las similitudes, se estudian los orígenes del vocabulario en los tópicos literarios, y se comentan usos especiales de algunos términos. El comparatismo nos permitirá también relacionar la cultura literaria con aportaciones de movimientos contemporáneos extraliterarios, como el Slow Mo. Se analiza la dimensión didáctica de esta literatura.

Palabras clave: Literatura comparada; Lengua española; Didáctica de la literatura.

Abstract: In this paper we are going to study two lexical groups: that of happiness and that of slowness, both in the didactic use made by two poets: Alfonso Canales (in his poem The years), and Luis Antonio de Villena (A Reading of The Georgics). Differences and similarities are examined, the origins of vocabulary are studied upon literary topics, and special uses of some terms are discussed. Comparativism will also allow us to relate the literary culture with contributions by contemporary extraliterary movements, such as the Slow Mo. The didactic dimension of this literature is analyzed.

Keywords: Comparative Literature; Spanish Language; Didactics of Literature.

\footnotetext{
${ }^{1}$ Este trabajo se ha realizado en el marco del Proyecto de Investigación «Felicidad y Literatura: eficacia social del discurso literario», de la Universidad de Salamanca, Programa IB, 2016, financiado por la Junta de Castilla y León.
} 


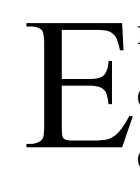

n este trabajo se estudiarán dos grupos léxicos —el de la felicidad y el de la lentitud-, ambos en el uso didáctico que les dan dos poetas: Alfonso Canales en su poema Los años, publicado en 1979, pero escrito, lógicamente, con alguna antelación, y Luis Antonio de Villena, que data en 1972 su Lectura de las Geórgicas. Los poetas pertenecen a generaciones distintas y planteamientos ideológicos y éticos muy dispares. El malagueño Canales se adscribe a la generación del 50. El madrileño Villena, a la del 70, en la estética novísima. Si Canales suele ser calificado de ortodoxo, a Villena se le aplica la categoría de heterodoxo (que él mismo ha acogido con gusto). Canales es cristiano. Villena, pagano. El primero ha rondado la idea del Bien. El segundo ha preferido las decadencias. A pesar de tantos antagonismos, los dos se reconocen en la línea más culta de la literatura española y occidental. Tienen en común muchas referencias, como, por ejemplo, su cercanía a los poetas de Cántico. Todo eso, junto con la casi sincronía con la que escribieron sus respectivos textos, propicia el enfoque comparatista que nos hará ver la poesía como enseñanza de vida: una literatura didáctica que a su vez nos facilitará la didáctica de la literatura, para recuperar así su utilidad clásica. El comparatismo permite también relacionar la cultura literaria con aportaciones de movimientos contemporáneos extraliterarios.

El léxico de la felicidad es rico en cualquier idioma. En español tiene una vertiente común perteneciente al acervo popular. Junto a él coexiste una gama léxica muy especializada que se ha transmitido en el lenguaje poético y que, como en el resto de las lenguas europeas, está arraigado doblemente en la tradición clásica grecolatina y en la bíblica. Canales pertenece sin duda a ambas. Por su parte, Villena ha elegido la herencia pagana junto con vocabularios y formas postvanguardistas. Y, si hubiera que situarlo en la Antigüedad, sin duda se sentiría cómodo en época helenística.

En cuanto a la defensa de la lentitud, su tradición literaria es asimismo larga, pues se remonta a los tópicos literarios de estirpe epicúrea, como el beatus ille. Fuera de la literatura, en la cultura contemporánea, su irrupción como uno más de los movimientos posmodernos se da en la década de 1980. El movimiento slow, que empezó como una defensa de la slow food frente a la fast food (concretamente contra un McDonalds de Piazza di Spagna en Roma), acabó siendo la apología general de todo un proyecto de vida más calmado. Propone frenar la aceleración desmesurada que la tecnología, la ciencia, y en general, el progreso sin límites han impuesto a la existencia humana. La percepción general es que la aceleración ilimitada de una vida humana (que biológicamente apenas ha cambiado) produce ansiedad a cada persona y a las sociedades de manera general. No era casual que pocos años antes se reforzara esta llamada a la lentitud encontrando referentes en otras culturas distintas de la occidental (por ejemplo, en la tradición hindú y las de influencia budistas), que proponían una vida menos angustiosa.

El movimiento slow adoptó un caracol como logo. Traducido a nuestra cultura literaria, diríamos que el caracol es su símbolo, su emblema moral: uno más como los de Alciato. No obstante, el slow 
puede incluirse entre los movimientos de cultura tecnológica y de masas. Es extraliterario. Lo que exploramos aquí es que esos mismos mensajes venían dándose desde hacía muchos siglos en la literatura occidental. De hecho, en España, una década antes y casi en el mismo año, estos dos poetas escribieron sendos poemas que vienen a decir lo mismo desde planteamientos vitales dispares y con sorprendentes semejanzas léxicas. Ese mismo mensaje se postulará después desde movimientos extraliterarios.

\section{Alfonso Canales: «Los años» (1979)}

Alfonso Canales es un poeta que muestra excepcionalmente su vinculación a la literatura como lenguaje sublime. Se le reconoció concediéndole honores altos. Pero también vivió tiempos de olvido. Se lo sitúa en la Generación del 50 por razones historiográficas, aunque en realidad su trayectoria poética permite calificarlo como independiente literario. Nació en Málaga en 1923 y murió en esa misma ciudad en 2010. Allí se dedicó profesionalmente al derecho, disciplina en la que se había doctorado. Pero fue, por encima de todo, poeta. Recibió el premio Nacional de Literatura en 1965 por su libro Aminadab y el Premio de la Crítica en 1973, por Réquiem andaluz. El poema «Los años» pertenece al libro El puerto, reconocido con el Premio Ciudad de Melilla en 1979 y publicado, como es habitual en ese galardón, en la prestigiosa colección Rusadir.

Canales es un poeta intelectual, aunque no necesariamente difícil. Usa la lengua española de una manera extraordinaria, enriqueciendo el vocabulario común por varias vías. Dos de ellas serán exploradas aquí: la variedad y la intensificación mediante su posición excepcional en el conjunto. Tomaremos «Los años» como texto que constituye una unidad de estudio plena, en lo linguí́stico y en lo literario. De hecho, está reconocido como uno de los grandes poemas de Canales, empezando por el criterio de su propio autor. En más de una ocasión manifestó su predilección por él. Por ejemplo, dos décadas más tarde lo recogió en una antología que se publicó en la colección Ciudad del paraíso bajo el título de Poemas mayores. En esa recopilación Alfonso Canales rescató no los más extensos (ni estrictamente los mejores), sino los textos que consideraba significativos y determinantes de su obra. Es más, eligió este poema para ofrecerlo manuscrito en las guardas del volumen, que, encuadernado en tapa dura, representaba una consagración definitiva del poeta. La posición excepcional y la reproducción del manuscrito como apertura y cierre el libro hacen de este poema el más significativo de entre los elegidos para representar lo más logrado de su autor ${ }^{2}$. Por eso «Los años» constituye una unidad literaria y lingüística de primer orden. No solo en el conjunto de la obra de su autor, sino en el de los textos españoles del siglo XX.

\section{LOS AÑOS}

Hermoso es morir joven

y dejar el recuerdo de la piel no tocada

\footnotetext{
${ }^{2}$ Por tanto el poema aparecía tres veces en el libro Poemas mayores: dos veces manuscrito en las guardas, y otra en el cuerpo mismo del texto.
} 


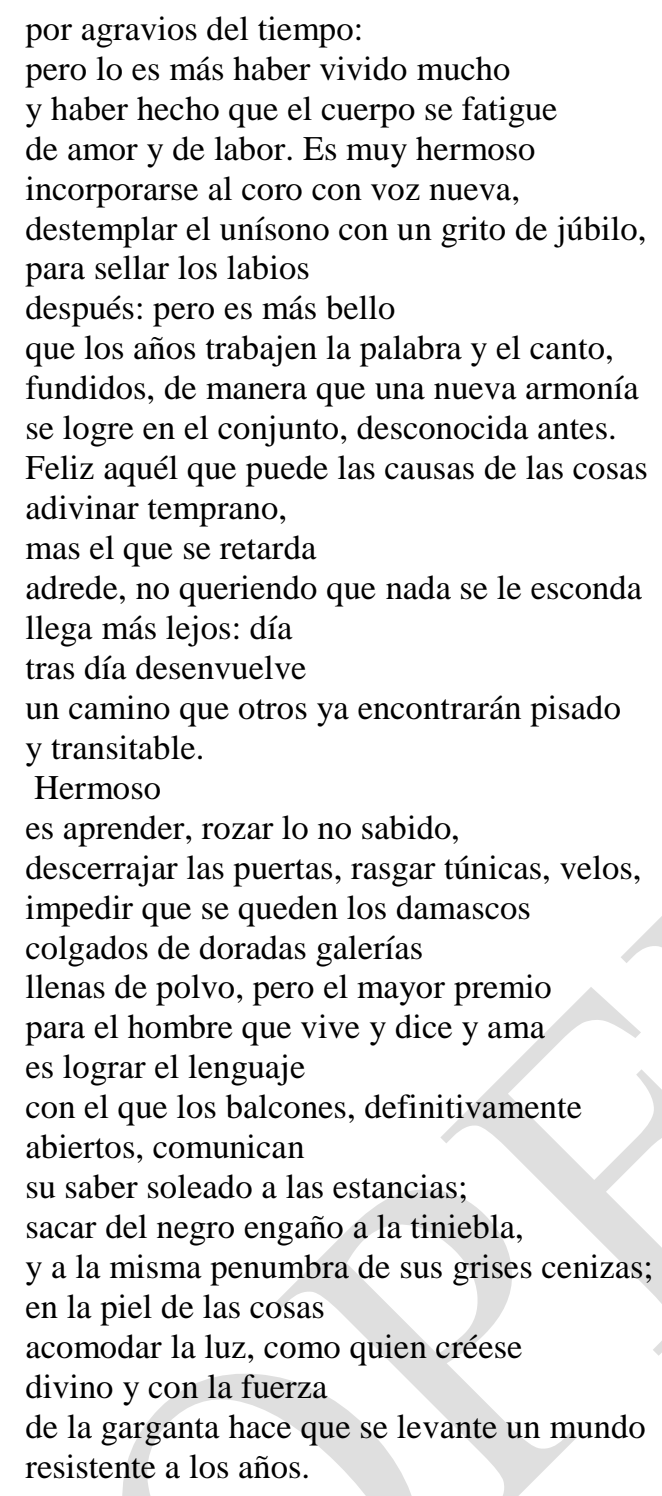

En esta didáctica de la felicidad que implica una didáctica de la literatura proponemos una mirada a los clásicos occidentales, que también son más lentos y liberan de ansiedad cultural. Tienen una doble utilidad: por una parte, sus contenidos defienden la serenidad; por otra, el hecho mismo de ser clásicos los sustrae de la angustia por el paso del tiempo. En el poema «Los años» confluyen estas dos líneas, dando lugar a un texto sublime. Es, probablemente, el mayor y el mejor de aquellos Poemas mayores. Es un texto que merece ser escuchado en la voz del poeta, leído en voz alta, y memorizado. Porque a la altura moral une su gran sentido musical.

Su obertura es un proverbio griego, que aseguraba que es bello morir joven. Sin embargo ahí surge la primera contraposición de las tres que se hallan en el poema: el poeta asegura que es mejor vivir mucho hasta cansarse («fatigado de amor y de labor»). La serie de contraposiciones didácticas enfrentan la enseñanza heredada de la tradición con el propio conocimiento del poeta, adquirido en su experiencia vital. La serie es de alto alcance literario y ético. Pero tiene la particularidad en lo lingüístico de estar conformada por tres oraciones adversativas. En las dos primeras la conjunción es 
'pero'; en la última y definitiva es 'mas', cuyo uso es culto y con connotaciones ligeramente arcaizantes:

1) Hermoso es morir joven (...) / pero lo es más haber vivido mucho

2) Es muy hermoso /incorporarse al coro con voz nueva, / pero es más bello

3) Feliz aquél que puede las causas de las cosas /adivinar temprano, / mas el que se retarda

El empleo que se da en esta tercera aparición de la fórmula adversativa 'mas' resulta asombrosamente creativa y dotada de una gran coherencia. Esta conjunción tiene en español un uso prácticamente reservado a la lengua escrita, culta o literaria. Las connotaciones arcaizantes que hemos señalados dotan de autoridad a lo que se afirma a continuación ${ }^{3}$. Aumenta la autoridad ética y didáctica de las palabras generales del poeta. Por ejemplo, 'mas', con su connotación arcaizante, está en relación con el verbo 'créese' que aparece casi al final del texto. La forma enclítica hace que pertenezcan a la misma serie: culta, escrita, arcaizante, con autoridad lingüística y literaria, y, por tanto, con más eficacia didáctica. Con toda esa fuerza el poeta se arma para contradecir la afirmación tradicional que acaba de citar, y que en realidad apela a Virgilio, la máxima autoridad poética y didáctica para un poeta culto como Canales.

La líneas centrales del poema iluminan la cuestión de la felicidad: «Feliz aquél que puede las causas de las cosas / adivinar temprano». No obstante, es una felicidad separada de la lentitud, pues Canales presenta ese conocimiento como temprano. Es una traducción casi literal de un verso áureo de Virgilio: «Felix qui potuit rerum cognoscere causas cognoscere potuit». En el poeta antiguo contiene el elogio del sabio, del que accede a los secretos de la felicidad. Parece que Virgilio elogiaba a otro gran poeta didáctico, Lucrecio, que había escrito su libro Sobre la naturaleza de las cosas (De rerum natura). A su vez, el maestro de Lucrecio, como el de Virgilio, era Epicuro. Una vez más nos remontamos al filósofo griego que prefirió vivir escondido, rodeado de sus amigos, como único estado del ser propicio para la felicidad. Curiosamente, el adverbio 'temprano' no está en Virgilio. Es un añadido de Canales, que, de este modo, evita que la traducción sea literal. El que adivina temprano el funcionamiento del mundo es el que va a la velocidad del mundo. O incluso podría llevar una velocidad más, pues parece ser el que se apresura.

\footnotetext{
${ }^{3}$ La Real Academia Española (2014a) lo da como sinónimo de 'pero’: «mas: 1. conj. advers. pero (\| para contraponer un concepto a otro)». La mejor precisión de su uso contemporáneo la ofrece Fundeu: «'Mas' se usa poco en el lenguaje común, y se emplea sobre todo en el lenguaje literario, con fines estilísticos. Sin embargo, fuera del lenguaje literario su uso es frecuente cuando en un texto se ha empleado la conjunción 'pero', para evitar la repetición de esta. En el castellano antiguo la conjunción 'mas' solía emplearse con el significado de 'sino', uso que se conserva en la plegaria conocida como "Padre nuestro [...] no nos dejes caer en la tentación, mas líbranos de todo mal [...]" De las conjunciones adversativas la más empleada hoy es 'pero', a diferencia del lenguaje antiguo, en que prevalecía 'mas'.» (Márquez Rodríguez, 2011). Dado que Canales es un poeta cristiano, no hay que desdeñar ese uso en la plegaria cristiana por excelencia, el Padrenuestro, en el que 'mas' tiene una función determinante. La presencia de 'mas' en su poema daría a la vez solemnidad virgiliana y cristiana a su defensa de la lentitud, y las dos solemnidades se prestan a esa didáctica literaria de lo lento.
} 
El verso de Virgilio está en el libro segundo de las Geórgicas: un libro que canta la vida en el campo. Nos encontramos con uno de los modelos de la literatura didáctica. El texto (Geórgicas, 2, 490 y ss.) dice exactamente, según la edición y la traducción de Espinosa Pólit (1961: 219):

\section{felix qui potuit rerum cognoscere causas, atque metus omnis et inexorabile fatum subiecit pedibus strepitumque Acherontis avari.}

Feliz quien del misterio de los seres pudo las causas penetrar, hollando los terrores del hado inexorable y el estruendo raptor del Aqueronte

Lo curioso es que en la traducción de Espinosa Pólit aparece a continuación una oración adversativa introducida por la misma conjunción que usa Canales: 'mas':
mas bienaventurado el que convive con los dioses campestres, Pan, Silvano y las Ninfas hermanas. No le azoran ni las fasces del pueblo, ni la púrpura fastuosa de los reyes; no le inquietan discordias fratricidas, ni incursiones de Dacos desde el Istro conjurados, ni el imperio de Roma, ni los reinos que en vano esquivan su fatal destino.

Más sorprendente aún resulta comprobar que esa explícita adversativa la introduce el traductor, porque Virgilio usa et:
fortunatus et ille deos qui novit agrestis
Panaque Silvanumque senem Nymphasque sorores.
illum non populi fasces, non purpura regum
flexit et infidos agitans discordia fratres, aut coniurato descendens Dacus ab Histro, non res Romanae perituraque regna; neque ille

En ese segundo momento Virgilio expresa en síntesis una enseñanza básica: el agricultor es más feliz incluso que el filósofo. El filósofo (Lucrecio o cualquier otro) consigue descifrar las causas de las cosas. Canales añade que lo hace tempranamente. En cambio el agricultor vive acorde con el paso del tiempo en la naturaleza, y está libre de las ambiciones del poder y del dinero. Canales en realidad transmite la enseñanza de Virgilio, subrayándola mediante la conjunción 'mas', que se encontraba en la traducción de Espinosa. Y en esa línea genética resuenan también los ecos de Fray Luis de León en su «Oda a la vida retirada».

Sin querer jugar con el retruécano, la literatura didáctica es la primera que hay que tener en cuenta para la didáctica de la literatura, ya que es la literatura que más se centra en lo concreto de enseñar a vivir. En ese sentido, Hesíodo se revela como su principal modelo. En la modernidad muchos poetas escriben literatura didáctica, sin que el lector se percate de que está ante ese género. El texto de 
Canales parece pertenecer a la poesía lírica, pero es propio de la didáctica. Y lo es conscientemente. Por ello Canales es un clásico.

En Virgilio, como en Hesíodo, el ideal del ser humano es el agricultor, que labora en su huerto. Está lejos de los excesos angustiosos de la vida urbana: de la acumulación innecesaria de riqueza, de los viajes largos y complicados, de la política, de los pleitos agobiantes en los juzgados. Todo eso nos suena, tanto lo malo como lo bueno, porque básicamente están intactos en nuestro mundo. También ahora hay una minoría que opta por retornar a la naturaleza y estar en contacto con la tierra. La defensa del trabajo sencillo va asociada a un ritmo de vida acorde con el de la naturaleza. Todo ello (la literatura y su didáctica reiterada en distintas épocas, la experiencia de muchos) nos recuerda que el que vive de acuerdo con la naturaleza tiene más posibilidades de ser feliz. La vida de cada uno se muestra así como una agricultura poética. Se entrevé una faceta ecológica en este poeta que parece tan intelectual. Canales recupera todos esos materiales y los pone al servicio de un proyecto de vida poético. Y, como en todo acto de comunicación poética, incide sobre el boceto vital del poeta y el del lector simultáneamente. Si nos atenemos a su biografía, el Canales que ejercía como abogado era muy distinto del Canales que vivía como poeta, como él mismo señaló a propósito del libro en el que está nuestro poema en una entrevista concedida para El País a Joaquín Marín (1979):

Abogado de profesión, Alfonso Canales, dedica a su despacho todo el día hasta las ocho de la tarde. "A esa hora cierro inflexiblemente, me tomo el té benigno y me transformo en otro hombre. A esa hora empiezo a ser poeta." Esta dualidad la expresa él con gracia andaluza: "Hasta las ocho de la tarde soy el doctor Jekyll; después empiezo a ser Mister Hide. Sin embargo, yo soy los dos y la verdad es que no prefiero una faceta a la otra. Pienso que el hombre tiene muchos registros, muchos más que la flauta de Hamelin, y no considero acertada esa manía de la gente de clasificar a las personas.

Alfonso Canales desarrolla creativamente (poéticamente) el léxico de la felicidad. Hace que lo sustenten por un lado los sustantivos y adjetivos tradicionales propios de tópicos literarios como el makarismós y el Beatus ille, pero también multiplica el significado particular específico de dos conjunciones y de un adverbio. Las dos conjunciones son dos sinónimos, las adversativas 'pero' y 'mas'. El adverbio es 'adrede', y se inserta en la brillante secuencia: «mas el que se retarda / adrede, no queriendo que nada se le esconda / llega más lejos». Es una secuencia extraordinaria cuyo conjunto apunta a la mayor eficacia, como corresponde a la lengua poética. Entre 'retarda' y 'adrede' hay una aliteración que llega a repetir casi todas las vocales y consonantes. La aliteración específica en /d/ se prolonga en 'nada', 'queriendo' y 'esconda'. Todas esas palabras quedan impregnadas del significado de lentitud que propicia la felicidad y el conocimiento verdadero. 'Adrede' es un adverbio cuyo significado es muy interesante. Según la Real Academia Española (2014b) se define así «A propósito, con intención deliberada», y sitúa su posible procedencia en el catalán adret, y este del latín ad directum. Es un vocablo que se usa sobre todo en la lengua común, pero al que Canales concede una significación fuerte y singular dentro del poema. La Academia advierte que el adverbio 'adrede' "es usado más en sentido peyorativo», es decir, para el que realiza una acción mala. Aquí el sujeto está 
optando por una acción buena ${ }^{4}$. El que alcanza la lentitud lo ha hecho «con intención deliberada» y para bien. Al asociar fónicamente 'adrede' con 'retarda', refuerza los vínculos semánticos entre ellos. De repente, y aquí encontramos la maestría poética de Canales, esos lazos lingüísticos se transmutan en vínculos éticos y didácticos: la lentitud se aprende y es voluntaria ${ }^{5}$. Lo mismo le sucede a la felicidad.

De un lado hemos visto que Canales intensifica el sentido de algunas palabras gramaticales, como son las conjunciones adversativas, hasta convertirlas en verdaderos ejes que articulan las dos zonas semánticas del poema: la primera es la de la sabiduría heredada aparente y la segunda es la del conocimiento verdadero, que estaba escondido en Virgilio también, y al que se suma la propia experiencia. Como novedad, el poema transmite su enseñanza fundamental. Su didáctica se difunde a través de una lengua literaria propia que debe ser enseñada a su lector. Alfonso Canales lleva a cabo una resemantización de las adversativas llevándolas a su máximo nivel significativo. Además de la eficacia estrictamente semántica, el léxico se ve reforzado por la posición de las palabras en el poema, que además de la sintaxis común se ve subrayada por los encabalgamientos o la situación en el verso (no sólo en la oración). Las tres apariciones de las adversativas se dan en posición inicial de verso. Lo mismo le sucede al adverbio 'adrede', que además está involucrado en un encabalgamiento abrupto de una gran fuerza connotativa.

El verso de Virgilio ha sido celebrado durante dos mil años por todas las generaciones de personas cultas. Alfonso Canales lo traduce magistralmente y le añade un giro nuevo: feliz el que adivina todo eso pronto (temprano), pero decide ir más lejos («el que se retarda / adrede»). El que se toma más tiempo para recorrer el mismo trayecto, llega a la misma meta, pero su camino es más feliz y más fructífero. Su felicidad no es sólo personal, sino social. Da fruto, como hemos visto en otros autores. Desbroza el camino para otros: les enseña a vivir. Y en esto se vislumbra una nueva didáctica. El que aprende sin prisa puede enseñar de manera más segura y duradera. La felicidad en el modelo clásico no es algo inmerecido: es algo que se intenta alcanzar practicando el bien y evitando el mal. Por eso se aprende de los maestros y después, cuando se ha aprendido y se ha vivido, se enseña a los que vienen detrás. La literatura guarda unas cuantas enseñanzas esenciales que no están en ningún otro lugar.

\section{Luis Antonio de Villena y su Lectura de las Geórgicas}

En la misma década, en 1972, probablemente unos años antes que Canales, trató el mismo asunto virgiliano Luis Antonio de Villena, un poeta que no puede ser más distinto de Canales. Novísimo, decadente, provocador, ateo y pagano... Nació en Madrid en 1951 y ha tenido una carrera literaria

\footnotetext{
${ }^{4}$ Otros literatos jugaron antes y después con el adverbio 'adrede' para aplicarlo al que actúa buscando el bien, siendo una de sus formas los hechos mismos de escribir o vivir, indistintos en la didáctica de la literatura. Ahí puede entrar Gerardo Diego (1932) con sus Poemas adrede. También Mario Benedetti (2008) con su «Vivir adrede».

5 'Adrede' es antónimo de 'acaso' en español, como han demostrado recientemente Espinosa Elorza y Sánchez Lancis (2006). Por tanto, ni la lentitud ni la felicidad pueden dejarse a lo azaroso, sino que deben ser cultivadas a propósito.
} 
EI léxico de la felicidad y de la lentitud en la didáctica de dos poetas...

completa como poeta, novelista, ensayista, articulista y traductor. También ha participado en algunos momentos de la cultura de masas, especialmente en la época de la Movida madrileña y también con apariciones en televisión, radio y prensa. Publicó esta Lectura de las Geórgicas en Syrtes, un libro que dio a la luz en 2000 pero que, según su relato, fue escrito justo después de su primer libro, Sublime solarium:

\section{LECTURA DE LAS GEÓRGICAS}

O fortunatos nimium, sua si bona norint, agricolas quibus ipsa, procul discordibus armis, fundit humo facilem victum iustissima tellus. (GEORGICON II, 458-460)

Fluminibus salices, crassisque paludibus alni nascuntur, steriles saxonis montibus orni; litora myrteis laetissima; denique apertos Bacchus amata colles, Aquilonem el frigora taxi. (GEORGICON II, 110-113)

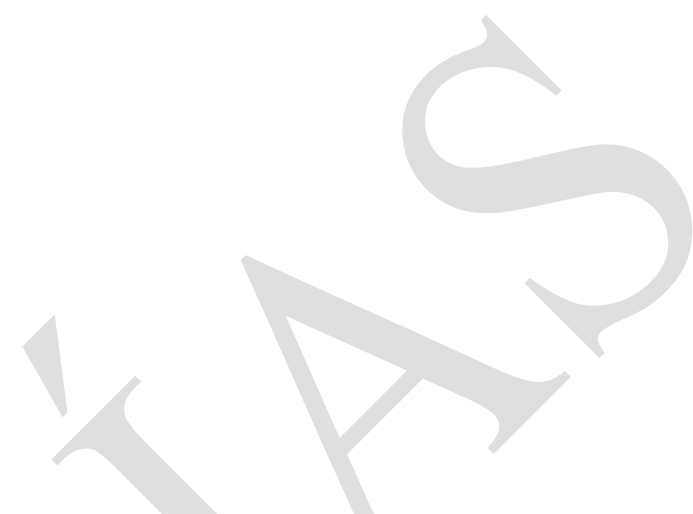

Pocas ciencias tan útiles como la horticultura, y pocas ciencias tan bellas. Enseña al hombre el tacto delicado de la flor, la delgadez fluvial de estambres y pistilos, la frágil armonía del corimbo, el color de los acerolos y el aroma lineal de la minutisa. Enseña la resistencia del trigo, el trato didascálico de abejas y nectarios, la belleza solar del polen y las diversas clases de hojas. Pero enseña también a ir por la montaña, olvidando las horas, a conocer el reino de las fuentes, donde levantan sus mármoles grandes comunidades de pececillos e insectos. A amar el flotar suave del espliego, el vaho de retamas y cambroños, la femínea riqueza de la bellorita. La horticultura enseña a tratar a las vides y a cuidar los ganados, pero en ella se encierra también el desprecio del oro, de la ambición, de los males de la envidia. Enseña la delicia del río y sus telares, el amor de las grutas llenas de hierba, la maravilla del sol y sus caballos o el devenir silente de las cosas. Feliz quien huye de las cosas que atan, del oro y los recuerdos, del deseo y sus trampas, feliz quien no otorga a las cosas valores infinitos, quien mide el tiempo por el reloj del tiempo, y detenido, callado entre los árboles, mira al sol y en su recuerdo permanece tan solo el volar de la húmida abeja y el brillo del agua bellísima y sus nereidas. Quien así detenido, inmutable, observa el ocaso y el alba, y goza de la belleza de las cosas, del jazmín, del endrino y del río, como de pequeñas, mas enormes maravillas. Pocas ciencias, de verdad, tan útiles como la horticultura y pocas en su solo enumerar, tan sobrio, tan enormemente bellas (Villena, 2000).

Villena introduce dos citas latinas cuya traducción a la lengua española nos dará algunas claves del texto contemporáneo. La primera es Geórgicas, 2, 458-460, que de nuevo vamos a leer en la versión de Espinosa Pólit (1961):

¡Oh bienaventurados los labriegos, si conociesen todo el bien que es suyo!

Lejos de las contiendas sanguinosas, fácil sustento, que del seno vierte, la tierra les ofrece, justiciera.

El siguiente pasaje que cita Villena es anterior en el libro de Virgilio. Geórgicas, 2, 110-113 (Espinosa Pólit, 1961:102):

Crecen sauces junto al agua, y alisos en el légamo de los paulares; el quejigo estéril entre los peñascales de las cumbres. Cunde espléndido el mirto en las riberas, 
la vid en las colinas asoleadas, los tejos donde arrecian Aquilones.

El lector queda en la duda de si esta descripción es puramente ornamental (lo que no sería discorde con el poema en prosa de Villena), aunque la clave posible estaría en el verso siguiente, no citado en latín: «Y admira cómo el mundo está rendido / hasta el postrer confín a los labriegos». El mundo entero sometido al modo de vida lento y feliz de los agricultores.

En realidad, la agricultura esconde lo que Villena ha llamado «Un arte de vida». En un poeta tan urbano no hay defensa verdadera de la vida del labriego, sino anhelo de lentitud y de felicidad. Para ello, un decadentista como él llegará a defender el principio clásico de la utilidad de la poesía, asociada a la belleza: «Pocas ciencias tan útiles como la horticultura, y pocas ciencias tan bellas. Enseña al hombre». Le ha interesado en todo momento la estética clásica y, es cierto, siempre ha sido un defensor de ella, pero desequilibrándola en beneficio de la belleza y renunciando a la utilidad. Le han interesado la paganidad y el homoerotismo más que la función educadora, o al menos ha puesto la última al servicio de los dos primeros. En cambio en este poema primerizo le interesa al poeta comunicar, enseñar a vivir, compartir su modelo de felicidad. Por eso pone la belleza al servicio de la utilidad. Su didáctica es egotista, como en Stendhal. Pero hay una literatura que enseña y que pide ser enseñada:

Enseña al hombre el tacto delicado de la flor, [...] Enseña la resistencia del trigo, el trato didascálico de abejas [...]. Pero enseña también a ir por la montaña, olvidando las horas, [...] La horticultura enseña a tratar a las vides [...]. Enseña la delicia del río y sus telares [...]

La anáfora 'enseña' articula esa literatura didáctica, cuya utilidad no se cumple si, a su vez, no es transmitida en la enseñanza. Es un término lexicológicamente autológico. Se señala a sí mismo. Nos indica que es literatura didáctica. Que estamos ante el género didáctico se concreta en un tecnicismo perfecto, 'didascálico', que se atribuye al trato de las abejas, pero que se refiere a la literatura, a la que se reduce toda esta horticultura celebrada desde la vida urbanita. En Villena es mucho más artificiosa, más egotista y más lírica que en Virgilio. También más elegíaca, porque canta un mundo perdido, al menos para el joven poeta que entona estas estrofas tan bellas como melancólicas.

Villena pone la felicidad en la lentitud, como Canales, y como el maestro común de ambos, Virgilio. Ya hemos identificado esa lentitud con la ausencia de prisas, porque se ha renunciado a la riqueza y al poder («el desprecio del oro, de la ambición, de los males de la envidia»). Esa lentitud surge del acomodo al ritmo del mundo, propio de quienes viven en el ciclo de lo natural: «enseña también a ir por la montaña, olvidando las horas, a conocer el reino de las fuentes». Sin relojes ni referencias artificiales del paso de las horas, el hombre feliz se deja llevar por esa ralentización que acaba en una detención asombrada: «quien mide el tiempo por el reloj del tiempo, y detenido, callado entre los árboles, mira al sol». La lentitud desemboca en silencio («callado», «silente»). Todo ese anhelo de felicidad está expresado en el makarismós. Para ello reitera el adjetivo 'feliz': «Feliz quien huye de las cosas que atan, [...] feliz quien no otorga a las cosas valores infinitos». Virgilio usa repetidamente beatus para referirse al agricultor. Canales usará 'feliz'. Es probable que haya un eco de un verso de Virgilio que ya hemos visto $-«$ Felix qui potuit rerum cognoscere causas cognoscere 
potuit» (Geórgicas, 2, 490)-. Villena no lo cita, pero su expresión se parece mucho. Celebra como feliz no al que conoce la causa de las cosas, sino al que «goza de la belleza de las cosas».

El hedonismo y el esteticismo de Villena se muestran muy distintos del enfoque sapiencial de Canales, mucho más ético. No obstante, es digno de mención que, igual que Canales y que Espinosa Pólit en su traducción, Villena use la conjunción adversativa 'mas': «como de pequeñas, mas enormes maravillas». El léxico de la felicidad es muy similar tanto en los adjetivos más significativos (que son los del tópico del makarismós, especialmente 'feliz'), como en la conjunción literaria y arcaizante, que dota de fuerza didáctica al texto. Los paralelismos, anáforas y perífrasis del texto de Villena forman parte de su lectura lenta. Es un poema de ritmo muy lento. Los cultismos forman serie, igual que en Canales. Villena usa 'mas' entre las palabras gramaticales, pero entre los sustantivos se recrea en términos raros, que detienen la comprensión y engendran lentitud en la lectura: 'corimbos', 'minutisa', 'nectarios' o 'bellorita' son ralentizadores del texto que en definitiva apuntan a la felicidad, porque muestran la percepción plena de las cosas y de las palabras, e impiden cualquier prisa.

\section{Conclusión}

Canales y Villena son dos poetas muy distintos, pero coinciden en ser cultos, doctos. Apelan a la tradición: sus poemas tan actuales nos vinculan como un link electrónico con Virgilio y con Epicuro. Sus poemas parecen líricos, pero son didácticos. Contienen un arte. Quizá el más difícil de todos: el arte de vivir. Pero, mientras Villena insiste en la estética, Canales señala directamente a la ética. Ambos compusieron en la década de los 70 del siglo XX sendos poemas con decidida intención didáctica. No es seguro cuál de los dos textos es anterior, pues Villena parece haberlo escrito antes, en 1972, pero lo publicó mucho después, en 2000. Canales lo publicó en 1979, pero es verosímil que lo escribiera antes de ese año. Los dos comparten un cierto espíritu de época, a pesar de que se sitúan en coordenadas ideológicas muy distintas. La defensa de la lentitud asociada a la felicidad se anticipa en la literatura a lo que el movimiento slow defenderá en la década siguiente, ya en los 80 . Pero su defensa vendrá de la mano de un movimiento de masas. Hay en ambos una coincidencia de fondo, crítica con las aceleraciones de finales del XX (y lo que ha transcurrido del XXI, que no parece haber soltado el acelerador). La eficacia de una didáctica literaria en ambos textos los hace válidos, más allá del retruécano aparente, para ser textos que se incorporen a la didáctica de la literatura, pues conjugan belleza y utilidad social. El estudio de los tópicos literarios se ha visto reforzado por el análisis lexicológico de algunos términos, sean conjunciones o adverbios, que en la poesía intensifican su significado. El análisis comparatista ha permitido establecer relaciones entre ambos textos. También entre ellos y las Geórgicas de Virgilio. Y, completando el mapa genético de la lentitud, entre esos tres textos literarios y un movimiento extraliterario como el slow, que defiende un ritmo pausado de vida con el mismo objetivo de lograr la felicidad humana. 


\section{Referencias Bibliográficas}

BenedetTI, M. (2008) «Vivir adrede», Cuadernos Hispanoamericanos, 691, pp. 9-12

CANALES, A. (1979): El puerto. Granada, Ubago-Rusadir. (1994): Poemas mayores: (1956-1983). Málaga, Ayuntamiento de Málaga-Ciudad del Paraíso.

Diego, G. (1932): Poemas adrede. México, Alcancía.

Espinosa Elorza, R. M. - SÁnChez LANCIS, C. E. (2006): «Adrede / acaso: historia de una antonimia», en Milka VILlayAndre LlamaZARES, ed., Actas del XXXV Simposio Internacional de la Sociedad Española de Lingüística. León, Universidad de León, pp. 464-485.

EsPinosa Pólit, A. (1961), Virgilio en verso castellano. Bucólicas. Geórgicas, Eneida. México, Jus. MARín, J. (1979): «Alfonso Canales, ganador del premio Melilla: la poesía es el menester más inútil y necesario», El País (11-9-1979); en http://elpais.com/diario/1979/09/11/cultura/305848805 850215.html (última consulta 12-6- 2017).

MÁrquez Rodríguez, A. (2011): «Con la lengua: las conjunciones (2)», FundéuBBVA; en http://www.fundeu.es/noticia/con-la-lengua-las-conjunciones-2-6822 (última consulta 12-62017)

Real Academia Española (2014a): Diccionario de la Lengua Española, s. v. 'mas'. Madrid, 23. ed.; en http://dle.rae.es/?id=OWE2P4C (última consulta 12-6- 2017). (2014b): Diccionario de la Lengua Española, s. v. 'adrede'. Madrid, 23. a' ed.; en http://dle.rae.es/?id=0pvPYG3 (última consulta 12-6- 2017)

VILLENA, L. A. de (2000): Syrtes. Barcelona, DVD. 